\title{
Neurological complications Secondary to Atlanto- occipital Assimilation: A Case Report
}

\author{
Ahmed Haroun and Mohammed Harraz* \\ Radiodiagnosis Department, Mansoura University, Egypt
}

Submission: 15 June, 2017; Published: July 10, 2017

*Corresponding author: Mohammed Mohammed Harraz, Radiodiagnosis Department, Faculty of Medicine, Mansoura University, Egypt, Tel: +2-01223275336/+2-050-2545556; Fax: +2-0402972914; Email: Harrazharraz@live.com

\section{Abstract}

Atlanto-occipital assimilation is one of the most common congenital anomalies observed at the craniocervical junction. It usually is asymptomatic but some have neurological problems such as myelopathy. We report a case of this malformation with unusual neurological symptoms which correlate with radiological findings. The knowledge of this variation may be of importance to orthopedic surgeons, neurosurgeons\& radiologists.

Keywords: Atlanto-occipital assimilation; Cranio-cervical junction; Myelopathy; Neurological complications

\section{Introduction}

Craniocervical abnormalities have been reported in various studies for many years. Atlas occipitalization or assimilation is one of the most common osseous congenital anomalies of the craniovertebral junction [1]. Atlas assimilation refers to the congenital fusion of the atlas with the base of the occipital bone, according to Yochum \& Rowe [2]. Some patients with atlas assimilation may be asymptomatic and others may experience many serious symptoms from neural compression caused either by encroachment into the foramen magnum or posterior arch projection into the spinal canal [3]. The following case report illustrates the radiographic abnormalities caused by this malformation.

\section{Case Presentation}

A 34-year-old male presented himself with a one-year history of numbness of all his fingertips in his both hand, hypoesthesia and posterior neck pain. On neurological examination, the patient had marked restriction in the range of motion of the neck in every direction because of low-neck pain radiating to the occipital region. He had no muscular atrophy .Hypoesthesia of both hands. Computed tomography (CT) revealed complete bony fusion of the $\mathrm{C} 1$ lateral masses and occipital condyles with reduced distance between $\mathrm{C} 1$ arches and occiput (Figure 1 \& 2). Almost complete fusion of $\mathrm{C} 2$ and $\mathrm{C} 3$ bodies and posterior elements, residual hypoplastic disc is noted (Figure 3). Tip of odontoid process is about $8 \mathrm{~mm}$ above McGregor's line (Normally less than $5 \mathrm{~mm}$ ) indicating basilar invagination (Figure 4). Craniovertebral angle is about 143 (Normal 150-180) indicating anterior compression on cervicomedullary junction. Cervical magnetic resonance imaging (MRI) revealed high signal intensity in the upper cervical spinal cord on the T2 weighted images opposite C2-3, which indicates spinal distress in the form of compression myelopathy (Figure 5 \& 6). Downward herniation of cerebellar tonsils (up to $10 \mathrm{~mm}$ ) predispose to more compression on cervicomedullary junction (Figure 6).

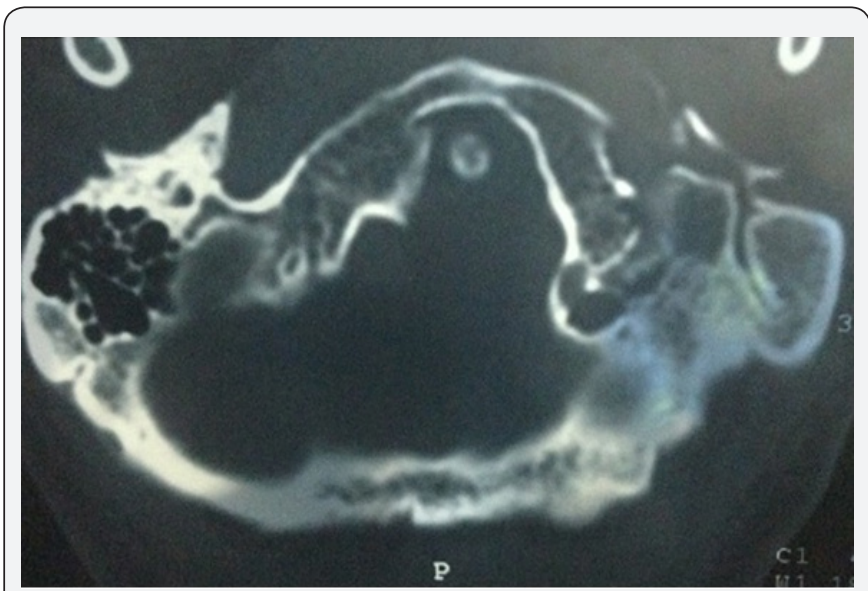

Figure 1: Figure 1: Axial CT revealed complete bony fusion of the $\mathrm{C} 1$ lateral masses and occipital condyles. 


\section{Open Access Journal of Neurology \& Neurosurgery}

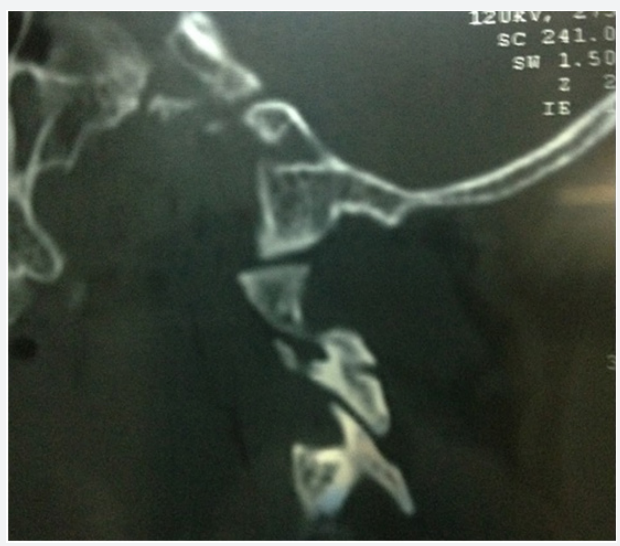

Figure 2: Sagittal CT revealed complete bony fusion of the $\mathrm{C} 1$ lateral masses and occipital condyles with reduced distance between $\mathrm{C} 1$ arches and occiput.

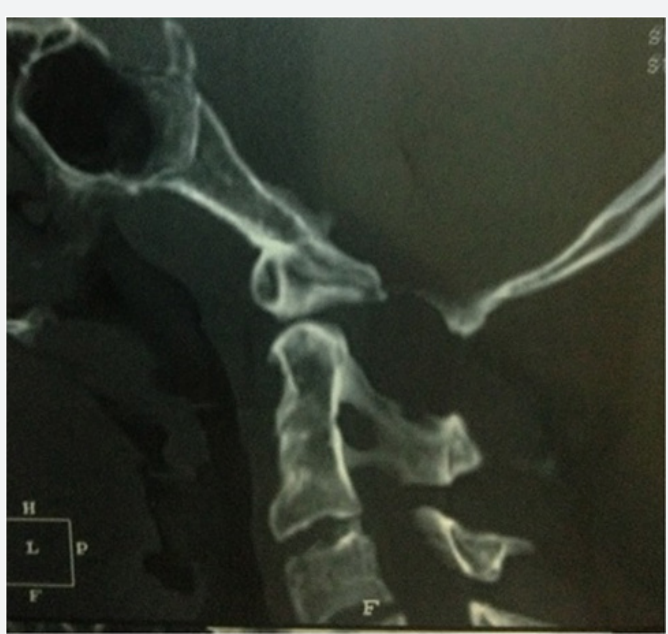

Figure 3: Sagittal CT revealed almost complete fusion of $\mathrm{C} 2$ and $\mathrm{C} 3$ bodies and posterior elements.

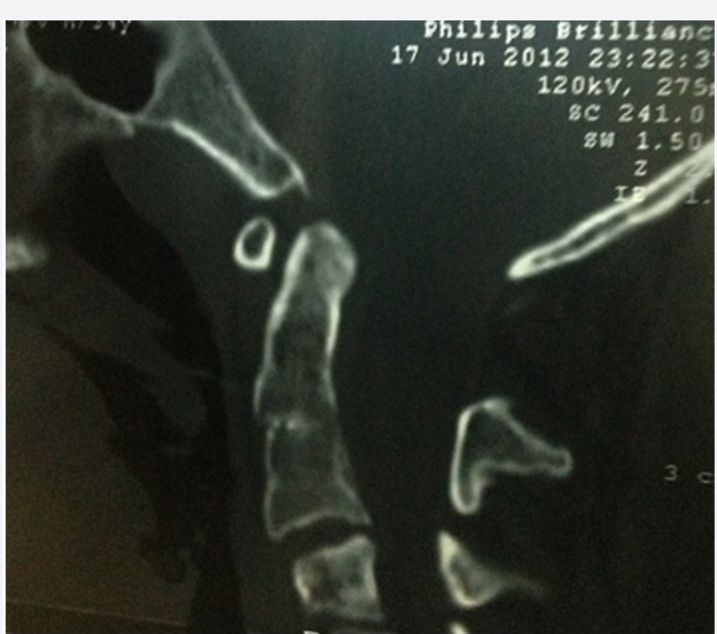

Figure 4: Sagittal CT revealed tip of odontoid process is about $8 \mathrm{~mm}$ above McGregor's line indicating basilar invagination.

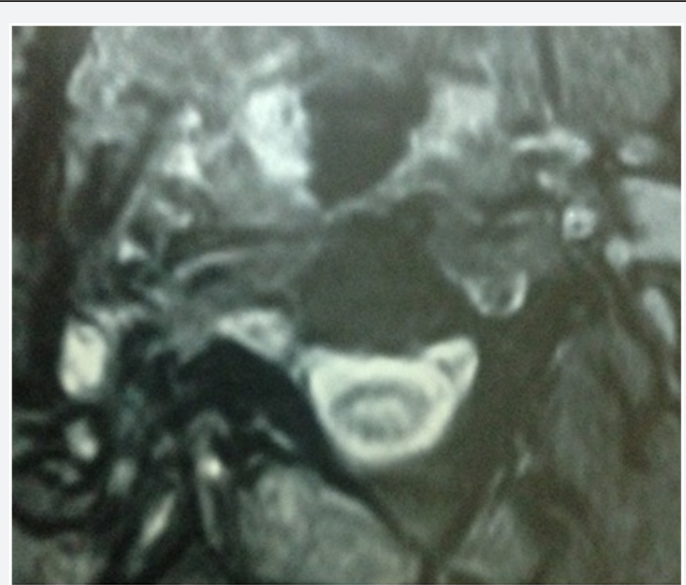

Figure 5: Axial T2WI revealed high signal intensity in the upper cervical spinal cord, which indicates compression myelopathy.

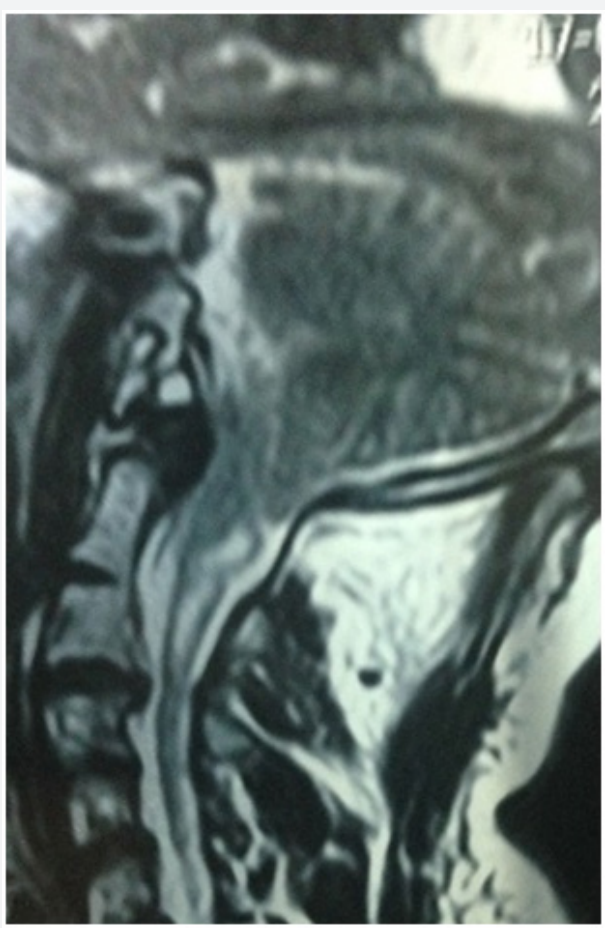

Figure 6: Sagittal T2WI revealed high signal intensity in the upper cervical spinal cord which indicates compression myelopathy and downward herniation of cerebellar tonsils predispose to more compression on cervicomedullary junction.

\section{Discussion}

Atlas assimilation is one of the most common congenital osseous malformations of the cranio-cervical junction. It is estimated to affect $0.08-3 \%$ of the general population. The fusion of the atlas with the occipital bone constitutes the anomaly. This condition may be complete or partial, with the latter being the most common [3], atlanto-occipital assimilation is associated with fusion of C2and C3 (occurs in 50\% of cases) or basilar invagination [4]. Patients with cranio-cervical junction 
anomalies often do not present neurological signs and symptoms before the age of 20. Atlas assimilation may be asymptomatic, but various signs and symptoms can occur in patients afflicted with it. These include headache, neck pain, numbness and pain in the extremities, weakness, ataxia, and symptoms connected to vertebral artery compression, which may each occur alone or with those of the spinal cord compression [5]. In the patient in this case study, congenital complete Atlanto-occipital assimilation associated with C2-3 fusion, Chiari 1 malformation, compression on cervicomedullary junction and myelopathy of upper cervical cord .We undertook this study with the aim of providing a more accurate report about the atlanto-occipital fusion, because of its interesting relationships with neuropathologies in adjacent structures.

\section{Conclusion}

Many variable types of atlas assimilation have been reported. Atlas assimilation may include alteration of the atlanto occipital articulation or narrowing of the spinal canal. Most of the abnormalities cause no typical symptom, but some patients have neurological problems which correlate with radiological findings.

\section{Ethical Approval}

Approval of the medical ethics committee was obtained for publication of this case report and accompanying images. The case was done in one private Radiological centers in Egypt in October 2014.

\section{References}

1. Lang J (1995) Atlas of Clinical Anatomy. In: Lang J (Ed.), Skull base and related structures. Shattauer, Stutgart, Germany, p. 54.

2. Yochum TR, Rowe LJ (1987) Essentials of skeletal radiology. In: Yochum TR, Rowe LJ (Eds.), Volume 1, ( $2^{\text {nd }}$ edn), William and Wilkins, Baltimore, USA, p. 3.

3. Kim KR, Lee YM, Kim YZ, Cho YW, Kim JS (2013) Cervical Myelopathy Secondary to Atlanto-occipital Assimilation: The Usefulness of the Simple Decompressive Surgery. Korean J Spine 10(3): 189-191.

4. Campos D, Silva TH, Ellwanger JH, Goerck ML, Kipper JF, et al. (2012) Atlanto-occipital fusion and its neurological complications: a case report. J Morphol Sci 29(2): 111-113.

5. Hensinger RN (1986) Osseous anomalies of the craniovertebral junction. Spine 11(4): 323-333.

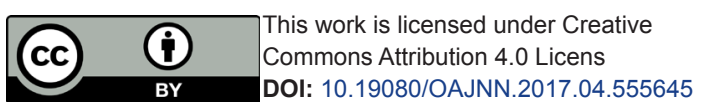

\section{Your next submission with Juniper Publishers will reach you the below assets}

- Quality Editorial service

- Swift Peer Review

- Reprints availability

- E-prints Service

- Manuscript Podcast for convenient understanding

- Global attainment for your research

- Manuscript accessibility in different formats

( Pdf, E-pub, Full Text, Audio)

- Unceasing customer service

Track the below URL for one-step submission https://juniperpublishers.com/online-submission.php 